\title{
Sociodemographic, clinical characteristics, and service utilization of young children diagnosed with autism spectrum disorder at a research center in Saudi Arabia
}

\author{
The road to autism spectrum disorder diagnosis
}

Abdullah M. Alotaibi, BCBA, Katelyn A. Craig, BCBA, Taghreed M. Alshareef, BSc, Elham S. AlQathmi, BSc, Sarah M. Aman, Dip, Hesham M. Aldhalaan, MD, Cheryl L. Oandasan, MD, FRCPC.

\begin{abstract}
الأهداف : تقييم كيفية وصول الأطفال الذين يشتبه إِصابتهم باضطراب طيف

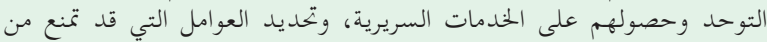

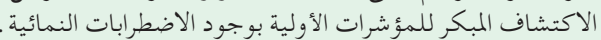

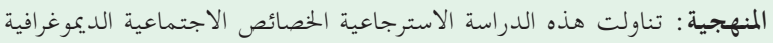

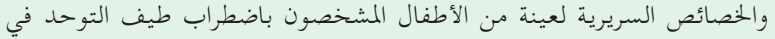

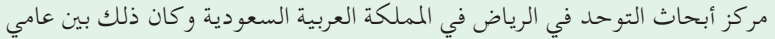

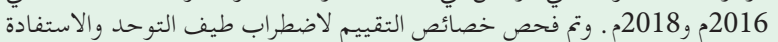

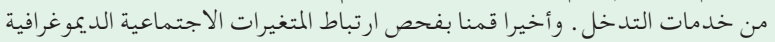

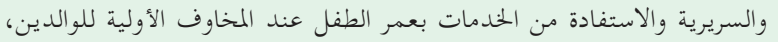

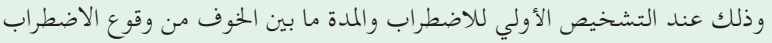
حتى تشخيصه.

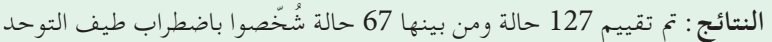

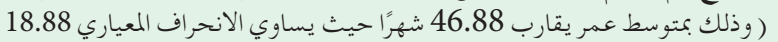

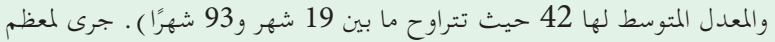

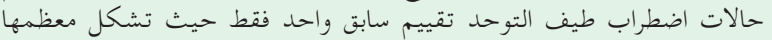

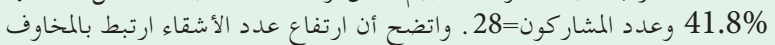

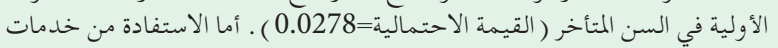

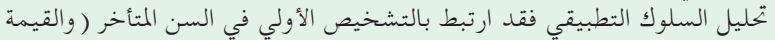

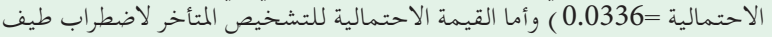
التوحد=0.0301.

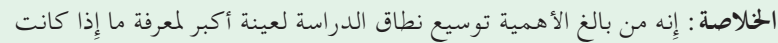

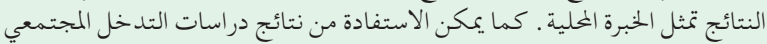

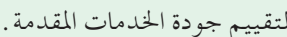

Objectives: To assess how clinical services are accessed and utilized by young children with suspected autism spectrum disorder (ASD) and identifying factors that prevent the early identification of developmental concerns and diagnosis.

Methods: This retrospective study examined the sociodemographic and clinical characteristics of a convenience sample of children diagnosed with ASD at the Center for Autism Research, Riyadh, Saudi Arabia between 2016 and 2018. The characteristics of ASD assessment and intervention service use were examined.
Additionally, we examined the association between sociodemographic, clinical, and service use variables with the child's age at the time of the parent's initial concern and first ASD diagnosis, and the time from first concern to diagnosis.

Results: Out of 127 cases, 67 were diagnosed with ASD (mean: 46.88 months, SD: 18.88, median: 42.00, range, 19-93). Most ASD cases had one previous assessment $(\mathrm{n}=28,41.8 \%)$. Higher sibling numbers were associated with a later age of first concern $(p=0.0278)$. Applied behavior analysis service utilization was associated with later age of first ASD diagnosis $(p=0.0336)$ and longer time to ASD diagnosis $(p=0.0301)$.

Conclusion: Larger sample size is needed to further investigate whether these findings are representative of the national experience. Community-based intervention outcome studies should assess the quality of services being provided.

Keywords: autism spectrum disorder, attention deficit disorder with hyperactivity, problem behavior, language development disorders, intellectual disability

Saudi Med J 2021; Vol. 42 (8): 878-885 doi: 10.15537/smj.2021.42.8.20210297

From the Department of Applied Behavior Analysis (Alotaibi); from the Center for Autism Research (Craig, AlQathmi, Aman, Aldhalaan); from the Department of Biostatistics, Epidemiology and Scientific Computing (Alshareef); from the Department of Mental Health (Oandasan), King Fahad National Center for Children's Cancer, Center for Autism Research, King Faisal Specialist Hospital and Research Center, Riyadh, Kingdom of Saudi Arabia.

Received 19th April 2021. Accepted 28th June 2021.

Address correspondence and reprint request to: Dr. Abdullah $M$. Alotaibi, Department of Applied Behavior Analysis, Autism Center of Excellence, King Faisal Specialist Hospital and Research Center, Riyadh, Kingdom of Saudi Arabia. E-mail: aalotaibi1406@gmail.com ORCID ID: https://orcid.org/0000-0001-5430-5625 
$\mathrm{A}_{\mathrm{n}}^{\mathrm{u}}$ utism spectrum disorder (ASD) is a complex neurodevelopmental condition characterized by deficits in social interaction and the presence of stereotypic movements and restricted interests in early childhood. Studies advice on the advantage of early screening for autism especially for children under 2 years. ${ }^{1}$ There is no cure for ASD; however, early diagnosis can lead to better rehabilitative outcomes as characterized by improved communication. ${ }^{2-4}$ It is advised to introduce autism screening tools for children even without symptoms manifestation, to insure early assessment and intervention services. ${ }^{1,5-7}$

Autism spectrum disorder is a global clinical concern; its median prevalence rate is 62 per 10000 children worldwide. ${ }^{8}$ However, reliable prevalence studies from Kingdom of Saudi Arabia (KSA) and the Arab world are scarce. ${ }^{9,10}$ Saudi studies have cited ASD prevalence rates of 18 per $10000^{11}$ and one in 167 , which translates to 59 per 10000 children. ${ }^{9}$ There are challenges which undermine the region's ability to conduct accurate ASD prevalence studies, including the shortage of trained professionals available to provide accurate diagnoses and the under-representation of diagnosed children due to a limited awareness of ASD in families and health professionals. ${ }^{12,13}$ These impact on the timing and quality of ASD diagnostic assessments and early intervention in the region.

A cross-sectional study in KSA was conducted among parents of ASD children. ${ }^{14}$ This study showed that parents who sought professional help at an earlier age was related to the early diagnosis, less severe ASD symptoms, residence in a major city, and younger children. Another cross-sectional study of Saudi children diagnosed with ASD at a tertiary care psychiatric clinic has reported the mean age at presentation of 6.3 years. ${ }^{11}$ Additionally, the onset of parents' concern is earlier for Saudi children when compared with their Egyptian counterparts; however, diagnosis and access to interventions are later in KSA. ${ }^{15}$ These studies are limited by sampling biases and differing characteristics; nonetheless, they highlight the need for data on the timing and experience of accessing diagnostic services for children with suspected ASD in KSA. This will increase our understanding of the factors affecting early access to ASD care.

Disclosure. Authors have no conflict of interests, and the work was not supported or funded by any drug company.
This retrospective study explored the sociodemographic and clinical characteristics of a cohort of children diagnosed with ASD at an autism research center in Riyadh, KSA. We described the services that were accessed from the time of first developmental concern to the diagnosis of ASD. In addition, we found the variables associated with age at parental onset of developmental concerns, age at initial ASD diagnosis, and the length of time from first concern to the first diagnosis. The study aims to contribute to the understanding of clinical characteristics of ASD in KSA and provide a profile of service utilization in KSA when parents are concerned on their child's development.

Methods. All cases attending the ASD diagnostic clinic at Center for Autism Research, King Faisal Specialist Hospital and Research Center, Riyadh, Saudi Arabia between December 2016 and July 2018 that met the inclusion criteria were included in the study (Figure 1). We evaluated 127 children (90 boys and 37 girls) with a mean age of 54.61 months (SD: 26.57, median: 49.0, range: 2-181 months). The participants were predominantly Saudi nationals $(78.7 \%)$ and lived in the central region of KSA (82.7\%). Sixty-seven cases were diagnosed with ASD (49 boys and 18 girls). The mean age was 46.88 months (SD: 18.88, median: 42.00, range: 19-93 months). The ASD sample was divided based on the presence $(n=48)$ or absence $(n=19)$ of a previous ASD diagnosis prior to the research clinic diagnostic assessment.

General informed consent had been obtained for data to be used for research purposes at the time of registration for the center services. A waiver for informed consent was submitted and approved by the office of research affairs (approval number: 2181-024) for this retrospective review study.

Children seen at the autism research center diagnostic clinic were self-referred by parents using an online registration form. No medical referral was required and evaluations were free of charge. Children who were accepted for comprehensive ASD evaluation were required to have passed a hearing evaluation. Additionally, at risk ASD symptoms were identified on an ASD screening instrument (modified checklist for autism in toddlers [M-CHAT] or social communication questionnaire [SCQ]) or clinical intake interview with members of the diagnostic team.

Diagnostic assessments were conducted by a multidisciplinary team of professionals that specialize in the assessment of ASD, including a medical doctor (child psychiatry, developmental pediatrician or pediatric neurologist), psychologist, speech-language pathologist, occupational therapist, and behavior therapist. Children were diagnosed following a multi-day evaluation 


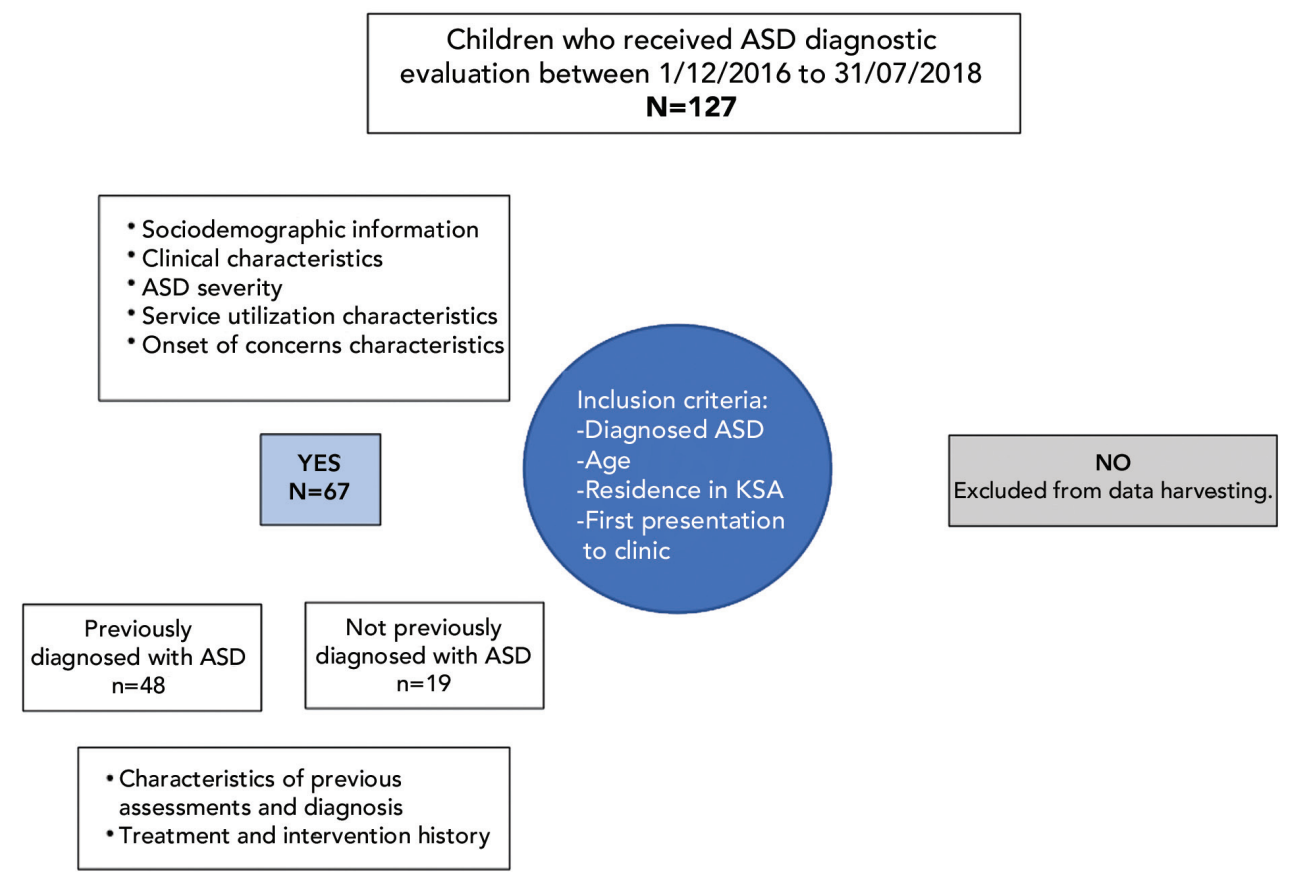

Figure 1 - Study design and variables. ASD: autism spectrum disorder, KSA: Kingdom of Saudi Arabia

that included a thorough developmental, medical, and psychosocial history and clinical assessment of developmental skills using observation, parent rating scales, and formal developmental and diagnostic tests that were non-standardized on the Saudi population. The ASD diagnosis was based on a consensus meeting of the diagnostic team using DSM-V diagnostic criteria, Vineland adaptive behavior scales (second edition), and autism diagnostic observation scale (second edition). ${ }^{16-18}$

Chart review and data harvesting were completed by 2 data abstractors familiar with ASD terminology. The data abstractors were trained on the chart review procedure, location of data, possible variations of terminology or description of chart data, coding procedure, and handling of conflicting or missing information.

Interrater reliability analysis using the Kappa statistic was performed to determine the consistency of each rater with a gold standard rater (consultant child psychiatrist). The mean reliability (kappa) for rater A was $0.860(p<0.001), 95 \%$ CI: [0.816-0.904] and B was $0.852(p<0.001), 95 \%$ CI: [0.808-0.896].

Data was stored on REDCap, a secure, web-based data collection tool hosted by King Faisal Specialist Hospital and Research Center, Riyadh, KSA, with its servers located within the hospital's secure data center.
Various search method was used to find previous related papers like PubMed, Saudi Digital Library, and Google scholar.

Charts were reviewed for information related to sociodemographic and clinical characteristics, perinatal factors, ASD severity, the onset of parental concern characteristics, service utilization, treatment, and intervention characteristics (Tables 1, 2 \& 3). Variables with $>15 \%$ missing data were excluded from the statistical analysis.

Statistical analysis. Data was analyzed using JMP version 14 , by the SAS Institute. ${ }^{14}$ Descriptive data was summarized and represented using frequency, percentage, central tendency measures, standard deviation, minimum, maximum, and quartiles. Differences between variables was measured using analysis of variance (ANOVA). A $p$-value $<0.05$ was considered significant, with a corresponding confidence level of $95 \%$.

Results. Tables $1 \& 2$ provides descriptive information on participant characteristics. Most children with ASD came from families with intact parental relationships (95.2\%) and with $\geq 2$ siblings (56.7\%). Consanguineous relationships are prevalent in the Middle East; our study 
Table 1 - Sociodemographic characteristics of ASD sample $(\mathrm{N}=67)$.

\begin{tabular}{|c|c|}
\hline Variables & $\mathrm{n}(\%)$ \\
\hline \multicolumn{2}{|l|}{ Gender } \\
\hline $\begin{array}{l}\text { Female } \\
\text { Male }\end{array}$ & $\begin{array}{l}18(26.9) \\
49(73.1)\end{array}$ \\
\hline \multicolumn{2}{|c|}{ Age (months) at time of clinic visit } \\
\hline $\begin{array}{l}<24 \\
24-47 \\
49-71 \\
72-95 \\
>96\end{array}$ & $\begin{array}{c}8(11.9) \\
30(44.8) \\
20(29.9) \\
9(13.4) \\
0(0)\end{array}$ \\
\hline \multicolumn{2}{|l|}{ Nationality } \\
\hline $\begin{array}{l}\text { Saudi } \\
\text { Non-Saudi }\end{array}$ & $\begin{array}{l}52(77.6) \\
15(22.4)\end{array}$ \\
\hline \multicolumn{2}{|l|}{ Area of residence } \\
\hline $\begin{array}{l}\text { Central } \\
\text { West } \\
\text { North } \\
\text { South } \\
\text { East }\end{array}$ & $\begin{array}{c}55(82.1) \\
3(4.5) \\
2(3.0) \\
3(4.5) \\
4(6.1)\end{array}$ \\
\hline \multicolumn{2}{|l|}{ Marital status of parents } \\
\hline $\begin{array}{l}\text { Married } \\
\text { Separated/divorced } \\
\text { Widowed }\end{array}$ & $\begin{array}{l}64(95.5) \\
2(3.0) \\
1(1.5)\end{array}$ \\
\hline \multicolumn{2}{|l|}{ Number of siblings } \\
\hline $\begin{array}{l}\text { None } \\
1 \\
2-4 \\
5-7\end{array}$ & $\begin{aligned} 6 & (9.0) \\
23 & (34.3) \\
32 & (47.8) \\
6 & (9.0)\end{aligned}$ \\
\hline \multicolumn{2}{|l|}{ Parents consanguinity } \\
\hline $\begin{array}{l}\text { Yes } \\
\text { No } \\
\text { Missing information }\end{array}$ & $\begin{array}{c}25(37.3) \\
40(59.7) \\
2(3.0)\end{array}$ \\
\hline \multicolumn{2}{|l|}{ Consanguinity type $(n=25)$} \\
\hline $\begin{array}{l}\text { First cousins } \\
\text { Second cousins } \\
\text { Same tribe }\end{array}$ & $\begin{array}{l}14(56.0) \\
7(28.0) \\
4(16.0)\end{array}$ \\
\hline \multicolumn{2}{|l|}{ Father level of education } \\
\hline $\begin{array}{l}\text { Primary school } \\
\text { Intermediate school } \\
\text { High school } \\
\text { Post-secondary education } \\
\text { Master's or higher } \\
\text { Missing information }\end{array}$ & $\begin{array}{c}1(1.5) \\
3(4.5) \\
9(13.4) \\
39(57.2) \\
10(14.9) \\
5(7.5)\end{array}$ \\
\hline \multicolumn{2}{|l|}{ Mother level of education } \\
\hline $\begin{array}{l}\text { Primary school } \\
\text { Intermediate school } \\
\text { High school } \\
\text { Post-secondary education } \\
\text { Master's or higher } \\
\text { Missing information }\end{array}$ & $\begin{aligned} 1 & (1.5) \\
3 & (4.9) \\
15 & (22.2) \\
33 & (49 . .6) \\
8 & (11.9) \\
7 & (10.5)\end{aligned}$ \\
\hline $\begin{array}{r}\text { ASD: autism spectrum dis } \\
\text { developmenta }\end{array}$ & D: pervasive \\
\hline
\end{tabular}

sample had $37.3 \%$ parental consanguinity. ${ }^{19,20}$ Of these relations, $56 \%$ were first cousins, $28 \%$ were second cousins, and $16 \%$ were from the same tribe.

Parental education. The educational level of parents was higher than the expected level from the general population of KSA. Most fathers had post-secondary
Table 2 - Clinical characteristics of ASD sample (N=67).

\begin{tabular}{lc}
\hline Variables & $\mathbf{n}(\%)$ \\
\hline Family bistory & \\
ASD, PDD & $17(25.4)$ \\
Speech delay & $28(41.8)$ \\
Intellectual disability & $15(22.4)$ \\
Attention-deficit/hyperactivity disorder & $13(19.4)$ \\
Psychiatric disability & $4(6.0)$ \\
Seizure disorder & $6(9.0)$ \\
Down's syndrome & $3(4.5)$ \\
Parent's initial concerns & \\
Language delay & $53(79.0)$ \\
Social skills delays & $55(82.1)$ \\
Stereotypic behavior or restricted repetitive interests & $31(46.3)$ \\
Disruptive behavior (hyperactive, agitated, & $11(16.4)$ \\
impulsive, aggressive) & \\
Inattention and distractibility & $12(17.9)$ \\
Self-injurious behavior & $2(3.0)$ \\
Cognitive delay & $0(0.0)$ \\
Motor delay & $3(4.5)$ \\
Other concerns & $3(4.5)$ \\
History of language regression & \\
Yes & $29(43.3)$ \\
No & $31(46.3)$ \\
Missing data & $7(10.4)$ \\
Reported previous diagnoses received & \\
ASD, PDD, Asperger's syndrome & $48(71.6)$ \\
Language delay/language disorder & $17(25.4)$ \\
Attention-deficit/hyperactivity disorder & $12(17.9)$ \\
Motor delay/motor disorder & $2(0.03)$ \\
Global development delay & $3(0.04)$ \\
Genetic disorder & $3(0.04)$ \\
ASD severity, median (mean $\pm S D)$ & \\
ADOS-2 calibrated severity score (CSS), n=65 & $7(6.49 \pm 1.59)$ \\
Vineland ABC composite score, n=53 & $62(61.1 \pm 7.81)$ \\
\hline ASD: autism spectrum disorder, PDD: pervasive developmental disorders, \\
$\quad$ ADOS: autism diagnostic observation schedule \\
\hline
\end{tabular}

education; $57.2 \%$ held a diploma or bachelor's degree and $14.9 \%$ held a master's or higher-level degree. Similarly, $49.3 \%$ of mothers held a post-secondary diploma or bachelor's degree, and 11.9\% held a master's or higher-level degree.

Clinical characteristics. A family history of ASD or pervasive developmental disorders (PDD) was reported in 17 cases $(25.4 \%)$. The most frequently reported positive family history was for speech delay $(n=28$, $41.8 \%)$, followed by intellectual disability $(n=15$, $22.4 \%)$, and ADHD ( $\mathrm{n}=13,19.4 \%)$. There were 3 cases with a family history of Down's syndrome.

Type of parent initial concerns. Parents' initial concerns were predominantly related to language $(79.0 \%)$ or social skill $(82.1 \%)$ delays, and stereotypic behavior/restrictive repetitive interests (46.3\%). Disruptive behavior (16.4\%) and inattention and distractibility (17.9\%) were also reported. 
Table 3 - Descriptive statistics: service utilization characteristics of ASD sample.

\begin{tabular}{lc}
\hline Variables & $\mathbf{n}(\%)$ \\
\hline Number of previous assessments prior to & \\
ASD diagnosis $(n=67)$ & \\
None & $11(16.4)$ \\
1 & $28(41.8)$ \\
2 & $17(25.4)$ \\
3 & $3(4.5)$ \\
$\geq 4$ & $1(1.5)$ \\
Missing data & $7(10.6)$ \\
Intervention in previous ASD diagnosis $(n=48)$ \\
Medication & $21(43.2)$ \\
Alternative treatment & $7(14.6)$ \\
Intervention services & $36(75.0)$ \\
Intervention in no previous ASD diagnosis $(n=19)$ \\
Medication & $8(42.1)$ \\
Alternative treatment & $3(15.8)$ \\
Intervention services & $9(47.4)$ \\
Type of intervention services $(n=45)$ & \\
Enrolled in daycare, preschool, & $20(44.4)$ \\
kindergarten, school, or special & $33(73.3)$ \\
education school & $8(17.8)$ \\
Speech therapy & $7(15.6)$ \\
Occupational therapy & $20(44.4)$ \\
Applied behavior analysis & $1(2.3)$ \\
Behavior therapy/training & $12(26.7)$ \\
Physiotherapy & $3(6.7)$ \\
Special education session & \\
Psychology & \\
Site of intervention services $(n=45)$ & \\
Clinic private/community & \\
Clinic - hospital based & \\
Home & \\
Center & $18(40.0)$ \\
School & $14(31.1)$ \\
& $23(51.1)$ \\
\hline \multicolumn{1}{c}{ ASD: autism spectrum disorder } & $17(37.8)$ \\
\hline
\end{tabular}

Service utilization characteristics. Most cases had received one previous assessment ( $\mathrm{n}=28,41.8 \%)$; $31.34 \%$ of cases had received $\geq 2$ previous assessments $(\mathrm{n}=21)$. Eleven had no previous assessments.

Intervention and treatment utilization. Most parents reported having received at least one treatment, such as medication, alternative treatment, or intervention services. Most children with a previous ASD diagnosis had received intervention services $(75 \%)$ or medication (48\%). Of the children with no previous ASD diagnosis $(n=19), 9$ had received intervention services and 8 had received medication treatment.

Onset of concern characteristics. The mean age of the

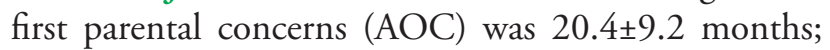
(median: 18.0, range: 3-54 months). The mean age at first ASD diagnosis (AOD) was 34.5 \pm 12.4 months (median: 33.0, range: 17-78 months). The mean time from first concern to first ASD diagnosis (TTD) was 14.1 \pm 9.4 months (median: 17.0, range: $1-50$ months).

Analysis of variance was performed to compare the study variables with the AOC, AOD, and TTD (Table 4). This showed a significant effect of the number of siblings at $\mathrm{AOC}[\mathrm{F}(3,63)=3.24, p=0.028]$; therefore, the parents of children with a greater number of siblings reported their first concerns later. Furthermore, there was a significant association between a family history of ASD and TTD; therefore, children with a positive family history of ASD had a longer delay from first concern to diagnosis.

There was a significant effect of disruptive behavior as the initial concern on AOD. This indicated that children whose parent's initial concerns were disruptive behavior were diagnosed with ASD at an older age. Additionally, their TTD was longer. A further significant association was found between AOC and parent initial concern of self-injurious behavior; however, this is interpreted with caution due to the small sample size. A positive family history of ASD was associated with TTD $[\mathrm{F}(1,65)=$ 6.2956, $p=0.0146]$.

Discussion. The mean age of first parental concern was 20.42 months in the current study, which is comparable to previous studies from the United States. Which studied a large sample $(\mathrm{N}=6214)$ and have reported mean ages of first concern diagnosis of 19.6 months and ASD diagnosis of 34.46 months. ${ }^{21}$ Therefore, there is a delay to first ASD diagnosis of 2.7 years. This contrasts with our findings of a mean age of first ASD diagnosis of 34.46 months and mean time to first ASD diagnosis of 14.07 months. This suggests that children in our sample were diagnosed more promptly after parents sought help for their identified developmental concerns.

Interestingly, our study results differ from a previous Saudi-based study published by Alnemary et al, ${ }^{12}$ who found the median age of the child when parents noted ASD concerns was 2.0 years, with reported shorter delays of 0.3 years to seek professional help, and 0.5 years before obtaining an ASD diagnostic assessment. These differences may be due to sample size and demographics; however, it does highlight the need for better understanding of the pathway to care for children at risk of ASD.

Our study found that parents' initial concerns consisted predominantly of ASD-specific concerns, such as social skill or language delays, and stereotypic behavior/restrictive repetitive interests. These findings were similar to a study by Al-Salehi et $\mathrm{al},{ }^{11}$ where 
Table 4 - Fixed-effects analysis of variance (ANOVA) comparing age of first concern, age of first ASD diagnosis, and time from concern to diagnosis with patient characteristics.

\begin{tabular}{|c|c|c|c|c|c|c|}
\hline \multirow{2}{*}{ Variables } & \multicolumn{2}{|c|}{ AOC } & \multicolumn{2}{|c|}{ AOD } & \multicolumn{2}{|c|}{ TTD } \\
\hline & F-ratio & $P$-value & F-ratio & $P$-value & F-ratio & $P$-value \\
\hline Number of siblings $(\mathrm{n}=66)$ & 3.2423 & $0.0278^{*}$ & 1.1176 & 0.3487 & 0.7762 & 0.5116 \\
\hline \multicolumn{7}{|l|}{ Family history $(n=66)$} \\
\hline $\begin{array}{l}\text { ASD } \\
\text { Speech delay } \\
\text { Intellectual disability } \\
\text { Attention-deficit/hyperactivity disorder } \\
\text { Psychiatric disability }\end{array}$ & $\begin{array}{l}0.2121 \\
1.1655 \\
2.1118 \\
3.1187 \\
2.2088\end{array}$ & $\begin{array}{l}0.6466 \\
0.3183 \\
0.1294 \\
0.0510 \\
0.1181\end{array}$ & $\begin{array}{l}2.2053 \\
0.3020 \\
0.5172 \\
1.9204 \\
2.6351\end{array}$ & $\begin{array}{l}0.1424 \\
0.7404 \\
0.5987 \\
0.1549 \\
0.0795\end{array}$ & $\begin{array}{l}6.2956 \\
0.3799 \\
1.0536 \\
1.4248 \\
0.7945\end{array}$ & $\begin{array}{l}0.0146^{*} \\
0.6855 \\
0.3547 \\
0.2481 \\
0.4562\end{array}$ \\
\hline $\begin{array}{l}\text { Seizure disorder }(\mathrm{n}=63) \\
\text { Down's syndrome }(\mathrm{n}=60)\end{array}$ & $\begin{array}{l}2.0959 \\
0.0069\end{array}$ & $\begin{array}{l}0.1317 \\
0.9340\end{array}$ & $\begin{array}{l}0.5198 \\
0.0069\end{array}$ & $\begin{array}{l}0.5972 \\
0.9340\end{array}$ & $\begin{array}{l}1.3800 \\
0.6511\end{array}$ & $\begin{array}{l}0.2593 \\
0.4230\end{array}$ \\
\hline \multicolumn{7}{|l|}{ Parent's initial concerns $(n=66)$} \\
\hline $\begin{array}{l}\text { Language delay } \\
\text { Social skills delays } \\
\text { Stereotypic behavior or restricted repetitive interests } \\
\text { Disruptive behavior - hyperactive, agitated, impulsive, aggressive } \\
\text { Inattention and distractibility } \\
\text { Self-injurious behavior } \\
\text { Motor delay }\end{array}$ & $\begin{array}{c}1.1162 \\
0.8809 \\
0.5973 \\
0.3048 \\
0.0583 \\
11.5057 \\
0.6220\end{array}$ & $\begin{array}{l}0.2947 \\
0.3514 \\
0.4424 \\
0.5828 \\
0.8100 \\
0.0012^{*} \\
0.4332\end{array}$ & $\begin{array}{l}0.0013 \\
0.2616 \\
0.4805 \\
4.8450 \\
0.5770 \\
2.7308 \\
0.1231\end{array}$ & $\begin{array}{r}0.9717 \\
0.6107 \\
0.4907 \\
0.0313^{*} \\
0.4502 \\
0.1033 \\
0.7268\end{array}$ & $\begin{array}{l}0.0040 \\
0.5221 \\
0.5560 \\
4.0284 \\
1.2831 \\
0.3031 \\
0.0060\end{array}$ & $\begin{array}{c}0.9501 \\
0.4726 \\
0.4586 \\
0.0489^{*} \\
0.2615 \\
0.5838 \\
0.9386\end{array}$ \\
\hline \multicolumn{7}{|l|}{ ASD symptom severity } \\
\hline $\begin{array}{l}\text { Vineland ABC composite score }(\mathrm{n}=52) \\
\text { The autism diagnostic observation schedule calibrated severity scores }(\mathrm{n}=64)\end{array}$ & $\begin{array}{l}0.4480 \\
1.4329\end{array}$ & $\begin{array}{l}0.9754 \\
0.2178\end{array}$ & $\begin{array}{l}1.4736 \\
1.9802\end{array}$ & $\begin{array}{l}0.1616 \\
0.0832\end{array}$ & $\begin{array}{l}0.4480 \\
0.9587\end{array}$ & $\begin{array}{l}0.9754 \\
0.4611\end{array}$ \\
\hline
\end{tabular}

communication impairment is the most common reason for ASD assessment referral. An additional study conducted by Alnemary et al, ${ }^{14}$ in 2017 also noted the largest initial concern for parents is language delay.

One surprising finding in our sample was that parents reported concerns later when there were a larger number of children in the family. This is not consistent with studies that have shown that parents with a typical child for comparison will be concerned at an earlier age. ${ }^{22,23}$ Provided the higher prevalence of larger families in KSA, this finding may suggest that the presence of many children within a family may interfere with the parents' ability to identify individual developmental concerns. This may be due to the practical challenges of managing a large family or the limited amount of time spent individually with each for the observation of developmental skills. Further confirmation of this finding with a larger sample size is needed. If confirmed, efforts to address this preventable delay in ASD identification and diagnosis would be needed via more stringent developmental surveillance.

Furthermore, the current study found an association between family history of ASD and a longer time to first ASD diagnosis. This finding contradicts other studies where earlier diagnosis is associated with having a sibling with ASD, among other factors. ${ }^{24,25}$ This may be due to a lack of specificity in our definition of family history: sibling versus distant relative or because many children were being evaluated after their initial ASD diagnosis when parents have become aware of the family history of ASD in the interim. A larger sample is needed to better understand this finding.

Early identification and intervention for ASD are associated with better developmental outcomes, adaptive functioning, and communication skills. However, our data did not support this construct. The lack of differentiation between ADOS-2 calibrated severity scores and Vineland adaptive behavioral composite scores based on the age of first ASD diagnosis may indicate that children did not access the effective amount or quality of ASD interventions after diagnosis. Further investigation of this finding with a larger national sample is needed. Additionally, intervention outcome studies with better regulation and quality accreditation for private sector clinics, centers, and therapists offering intervention services in the community should be conducted. This will help to determine how to support the development of post-diagnostic ASD services in KSA, which improve developmental outcomes.

Speech therapy was used the most as an intervention by the participants in this study. Interestingly, few participants used occupational and applied behavior 
analysis (ABA) therapy, which are commonly used intervention services worldwide. Applied behavior analysis service use in KSA is significantly lower when compared with other Gulf cooperation council countries. Kelly et al, ${ }^{26}$ have reported that $49.58 \%$ of their participants use ABA in the United Arab Emirates. The availability of credentialed ABA professionals is limited is KSA; only 2 organizations in the country advertise services provided by credentialed $A B A$ therapists. ${ }^{26}$ Furthermore, ABA is not a government regulated profession, which increases the barriers to access the therapy.

Study limitations. Most participants of this study resided in central KSA (82.1\%) where the study site is situated; therefore, the findings cannot be generalized for a national sample. Furthermore, the sample size was small, and sample and selection biases must be considered.

Autism care and service delivery are developing in KSA. Further elucidation of how families seek help regarding early child developmental concerns is required. This study offers an assessment of the experiences of a small sample of families. Importantly, future studies should have a broader scope, larger sample size, and more uniform sociodemographic distribution to ensure the findings best represent the national experience.

In conclusion, our study raises questions on what occurs after an ASD diagnosis, even when it is relatively early and timely. Further study of the current pathways of care, outcome studies for available intervention programming, descriptive studies surveying methods of diagnostic approaches, and communication practices between diagnosticians and those providing intervention are needed to a better understanding of the system's strengths and weaknesses.

Ultimately, regulated pathways of ASD diagnosis and care are needed. These will encompass provider credentialing, clinical supervision, and improving availability to key ASD intervention services via student scholarship. This will improve the number of specialists in disciplines such as ABA and occupational therapy, child psychiatry, pediatric neurology, and developmental pediatrics. Additionally, it will ensure affordable quality ASD diagnostic and intervention services.

Acknowledgment. The authors gratefully acknowledge the Center for Autism Research Administration and Diagnostic Clinic, Riyadh, Kingdom of Saudi Arabia team for their cooperation throughout the study and for their support in completing the manuscript. The authors would also like to acknowledge the contribution of Mr. Abdulmoniem Eldali, technical specialist, formerly of King Faisal Specialist Hospital and Research Center, Riyadh, Kingdom of Saudi Arabia for his assistance with early data analysis. We also appreciate the contribution of Fatin A. Alotaibi for translation assistance. Lastly, we would like to thank Wordvice for their English language editing.

\section{References}

1. Zwaigenbaum L, Bauman ML, Fein D, Pierce K, Buie T, Davis PA, et al. Early screening of autism spectrum disorder: recommendations for practice and research. Pediatrics 2015; 136: S41-S59.

2. Schreibman L, Dawson G, Stahmer AC, Landa R, Rogers SJ, McGee GG, et al. Naturalistic developmental behavioral interventions: empirically validated treatments for autism spectrum disorder. J Autism Dev Disord 2015; 45: 2411-2428.

3. Green J, Charman T, Pickles A, Wan MW, Elsabbagh M, Slonims V, et al. Parent-mediated intervention versus no intervention for infants at high risk of autism: a parallel, singleblind, randomised trial. Lancet Psychiatry 2015; 2: 133-140.

4. Green J, Pickles A, Pasco G, Bedford R, Wan MW, Elsabbagh $\mathrm{M}$, et al. Randomised trial of a parent-mediated intervention for infants at high risk for autism: longitudinal outcomes to age 3 years. J Child Psychol Psychiatry 2017; 58: 1330-1340.

5. Zwaigenbaum L, Bauman ML, Choueiri R, Kasari C, Carter A, Granpeesheh D, et al. Early intervention for children with autism spectrum disorder under 3 years of age: recommendations for practice and research. Pediatrics 2015; 136: S60-S81.

6. Pasco G. The value of early intervention for children with autism. Paediatr Child Health (Oxford) 2018; 28: 364-367.

7. Rogers SJ, Vismara L, Wagner AL, McCormick C, Young G, Ozonoff S. Autism treatment in the first year of life: a pilot study of infant start, a parent-implemented intervention for symptomatic infants. J Autism Dev Disord 2014; 44: 2981-2995.

8. Elsabbagh M, Divan G, Koh YJ, Kim YS, Kauchali S, Marcín $\mathrm{C}$, et al. Global prevalence of autism and other pervasive developmental disorders. Autism Res 2012; 5: 160-179.

9. Alnemary F, Alnemary F, Alamri Y. Autism research: where does the Arab world stand? Rev J Autism Dev Disord 2017; 4: 157-164.

10. Al Zahrani A. Prevalence and clinical characteristics of autism spectrum disorders in school-age children in Taif-KSA. Int J Med Sci Public Health 2013; 2: 578-583.

11. Al-Salehi SM, Al-Hifthy EH, Ghaziuddin M. Autism in Saudi Arabia: presentation, clinical correlates and comorbidity. Transcult Psychiatry 2009; 46: 340-347.

12. Alnemary FM, Aldhalaan HM, Simon-Cereijido G, Alnemary FM. Services for children with autism in the Kingdom of Saudi Arabia. Autism 2017; 21: 592-602.

13. Al Shirian S, Al Dera H. Descriptive characteristics of children with autism at autism treatment center, KSA. Physiol Behav 2015; 151: 604-608.

14. Alnemary F. The Journey from Diagnosis to Services for Parents of Children with Autism Spectrum Disorder in Saudi Arabia [dissertation]. Los Angeles (CA): University of California, Los Angeles; 2017.

15. Hussein H, Taha GR, Almanasef A. Characteristics of autism spectrum disorders in a sample of egyptian and saudi patients: transcultural cross sectional study. Child Adolesc Psychiatry Ment Health 2011; 5: 34.

16. Esler AN, Bal VH, Guthrie W, Wetherby A, Ellis Weismer S, Lord C. The autism diagnostic observation schedule, toddler module: standardized severity scores. J Autism Dev Disord 2015; 45: 2704-2720. 
17. Gotham K, Pickles A, Lord C. Standardizing ADOS scores for a measure of severity in autism spectrum disorders. J Autism Dev Disord 2009; 39: 693-705.

18. Yang S, Paynter JM, Gilmore L. Vineland adaptive behavior scales: II profile of young children with autism spectrum disorder. J Autism Dev Disord 2016; 46: 64-73.

19. el-Hazmi MA, al-Swailem AR, Warsy AS, al-Swailem AM, Sulaimani R, al-Meshari AA. Consanguinity among the Saudi Arabian population. J Med Genet 1995; 32: 623-626.

20. Warsy AS, Al-Jaser MH, Albdass A, Al-Daihan S, Alanazi M. Is consanguinity prevalence decreasing in Saudis? A study in two generations. Afr Health Sci 2014; 14: 314-321.

21. Rosenberg RE, Landa R, Law JK, Stuart EA, Law PA. Factors affecting age at initial autism spectrum disorder diagnosis in a national survey. Autism Res Treat 2011; 2011: 874619.

22. Zablotsky B, Colpe LJ, Pringle BA, Kogan MD, Rice C, Blumberg SJ. Age of parental concern, diagnosis, and service initiation among children with autism spectrum disorder. Am J Intellect Dev Disabil 2017; 122: 49-61.
23. Herlihy L, Knoch K, Vibert B, Fein D. Parents' first concerns about toddlers with autism spectrum disorder: effect of sibling status. Autism 2015; 19: 20-28.

24. Bickel J, Bridgemohan C, Sideridis G, Huntington N. Child and family characteristics associated with age of diagnosis of an autism spectrum disorder in a tertiary care setting. J Dev Behav Pediatr 2015; 36: 1-7.

25. Mazurek MO, Handen BL, Wodka EL, Nowinski L, Butter E, Engelhardt CR. Age at first autism spectrum disorder diagnosis: the role of birth cohort, demographic factors, and clinical features. J Dev Behav Pediatr 2014; 35: 561-569.

26. Kelly M, Alireza I, Busch H, Northrop S, Al Attrash M, Ainsleigh S, et al. An overview of autism and applied behavior analysis in the Gulf Cooperation Council in the Middle East. Rev J Autism Dev Disord 2016; 3: 154-164. 